Choosing the Best Mattress: An Experiment in Testing Whether Individuals Choose a Bed That Leads to Improved Sleep

Sean O. Hogan, Jack D. Edinger, Gayle S. Bieler, and Andrew D. Krystal

August 2011 


\section{About the Authors}

Sean O. Hogan, PhD, is a former project director in RTI International's Survey Research Department. He participated in the design of the study and served as its project director between 2008 and 2011.

Jack D. Edinger, $\mathrm{PhD}$, is a senior psychologist at the Veterans Affairs Medical Center in Durham, North Carolina.

Gayle S. Bieler, MS, is a senior statistician at RTI International. Ms. Bieler led design and implementation of statistical data analysis.

Andrew D. Krystal, MD, is director of the Quantitative EEG Laboratory at Duke University Medical Center, and an assistant professor in Duke's Department of Psychiatry and Behavioral Sciences.
This publication is part of the RTI Press Research Report series.

RTI International

3040 Cornwallis Road

PO Box 12194

Research Triangle Park, NC

27709-2194 USA

Tel: $\quad+1.919 .541 .6000$

Fax: $\quad+1.919 .541 .5985$

E-mail: rtipress@rti.org

Web site: www.rti.org

\section{RTI Press publication RR-0016-1108}

This PDF document was made available from www.rti.org as a public service of RTI International. More information about RTI Press can be found at http://www.rti.org/rtipress.

RTI International is an independent, nonprofit research organization dedicated to improving the human condition by turning knowledge into practice. The RTI Press mission is to disseminate information about RTI research, analytic tools, and technical expertise to a national and international audience. RTI Press publications are peer-reviewed by at least two independent substantive experts and one or more Press editors.

\section{Suggested Citation}

Hogan, S. O., Edinger, J. D., Bieler, G. S., and Krystal, A., D. (2011). Choosing the best mattress: An experiment in testing whether individuals choose a bed that leads to improved sleep (RTI Press publication No. RR-0016-1108). Research Triangle Park, NC: RTI Press. Retrieved [date] from http://www.rti.org/rtipress.
(C)2011 Research Triangle Institute. RTI International is a trade name of Research Triangle Institute.

All rights reserved. Please note that this document is copyrighted and credit must be provided to the authors and source of the document when you quote from it. You must not sell the document or make a profit from reproducing it.

doi:10.3768/rtipress.2011.rr.0016.1108

www.rti.org/rtipress 


\section{Choosing the Best Mattress: An Experiment in Testing Whether Individuals Choose a Bed That Leads to Improved Sleep}

\author{
Sean O. Hogan, Jack D. Edinger, Gayle S. Bieler, and \\ Andrew D. Krystal
}

\section{Contents}

Introduction

2

Methods

Study Design and Sample

Statistical Methods

Results

Actigraphically Determined Bed Ranking (Motion Bed Rank)

Sleep Quality Bed Ranking

8

Self-Selected Versus Actigraphically Determined Best Bed

Discussion

Acknowledgments Inside back cover

A comfortable mattress is said to be an essential ingredient in a good night's sleep, but we have little understanding of the effects of sleep surface on sleep outcomes such as daytime drowsiness or energy. Most studies devoted to testing the effects of sleep surface on sleep have been hampered by methodological shortcomings; these include having small numbers of subjects and evaluating a narrow array of bedding systems. We hypothesized that motion and selfreported measures of sleep quality and outcomes would demonstrate that the optimal mattress would differ from person to person. We hypothesized that individuals would be able to select one mattress from among several under showroom circumstances that would lead to optimal rest. We find that optimal mattress firmness varies among individuals and is reflected, at least to a degree, by overnight motion. When allowed to test mattresses in a typical showroom experience, individuals choose a mattress that does not minimize overnight motion and maximize perceived sleep quality. This suggests that they may not be receiving the health benefits that come from optimal rest. Therefore, both manufacturers and sleep scientists could improve sleep outcomes by testing ways to help consumers select a mattress. 


\section{Introduction}

A growing body of literature indicates the effects of sleep on health, ability to function, and quality of life (Alapin et al., 2001; CDC, 2007; Elmenhorst et al., 2008; Hamilton et al., 2007; Hanel, Dartman, \& Shishoo, 1996; NIH, 2003a, 2003b; Roberts, Roberts, \& Duong, 2008; Van Dongen, Maislin, Mullington, \& Dinges, 2003). A comfortable mattress is commonly assumed to be an essential ingredient in a good night's sleep (Better Sleep Council, 2008b). However, we have little understanding of the effects of sleep surface on sleep outcomes such as daytime drowsiness or energy. Moreover, most studies devoted to testing the effects of sleep surface on sleep have been hampered by methodological shortcomings; these include having small numbers of subjects and evaluating a narrow array of bedding systems (Lopez-Torrez, Porcar, Solaz, \& Romero, 2008).

When trying to select a comfortable mattress, or one that will provide optimal sleep, consumers confront the decision to choose from among several mattresses. Sources of information easily accessible to laypersons (see for example reports by the Better Sleep Council, 2008b; and Consumer Reports, 2005) essentially tell consumers to trust their own judgment. In other words, consumers are told to base their decision on an in-store experience of lying on, sitting on, and feeling the mattresses. Unfortunately, the scientific literature is not much more helpful to health care providers who might wish to offer guidance to the layperson choosing a mattress. This literature has been silent on the extent to which individuals should evaluate a mattress, or whether they are capable of selecting the mattress that leads to best outcomes, such as quality of rest, reduced drowsiness, or increased daytime energy. In addition, we found that the current literature typically suffers from three shortcomings that have deprived experts and laypersons alike of this knowledge (Krystal, Edinger, Bieler, Mladsi, \& Hogan, 2011). These deficiencies are that most studies of mattress effects on sleep have relied on (1) a small number of people enrolled in the study, (2) a narrow array of test mattresses, ${ }^{1}$ and (3) a narrow focus on individuals suffering from a chronic sleep ailment of some sort.

To help address this deficiency in knowledge, we recruited a sample of 128 healthy adults (referred to as subjects, participants, or individuals) and asked them to sleep on an array of seven mattresses for up to 1 month each. We recorded measures of overnight motion (with a sensor called an actigraph), and participants completed diary reports of sleep quality and daytime function. According to the collected data, individuals vary substantially in the degree of mattress firmness that reduces their morning pain and optimizes their sleep experience and subsequent daytime functioning (Krystal et al., 2011). Along with validating the methods of measurement, we reported that a slight increase in sleep efficiency (actigraphically measured time devoted to sleep actually spent sleeping) can lead to improved quality of sleep as reported in diary observations.

In this, our second report from this study, we build on the foundation of our earlier paper (Krystal et al., 2011). For this study, we hypothesized that overnight actigraphic motion measurements (which indicate sleep and awake periods during the time devoted to sleep) and self-reported diary measures of sleep would demonstrate that an optimal mattress could be identified for an individual and that the "best" mattress would differ from person to person. We also hypothesized that changes in measured overnight motion would coincide with other measures of sleep and daytime functioning (e.g., as daytime energy and drowsiness). Finally, we hypothesized that individuals would be able to rely on conventional shopping procedures to select one mattress from among several under showroom circumstances that would lead to optimal rest. Here we address these questions. As in the last paper, we relied on a randomized, singleblind, within-subject crossover study examining multiple levels of mattress firmness in a large sample of individuals without complaints of pain or sleep difficulty.

${ }^{1}$ In this report, the terms mattress and bed are used interchangeably. 


\section{Methods}

\section{Study Design and Sample}

Our previous paper explains in detail our study procedures, sample selection, and methods of measurement. We summarize our methods here to inform readers of the basic elements of our protocol.

We recruited a convenience sample of 128 healthy adults who lived in the Raleigh-Durham area of North Carolina. Table 1 describes the age, body mass index (BMI), gender, race, and partnership status of our sample members. None of the subjects had a sleep-affecting disease, sleep-disrupting prescription drug regimen, or lifestyle that is known to interrupt sleep (e.g., frequent travel, infants to care for, overnight work shift).

\begin{tabular}{|c|c|c|}
\hline Variable & Sample Size & Mean or Percentage Distribution \\
\hline Age in years & 128 & 40.4 (Range: 24.0-68.0) \\
\hline BMI & 128 & 25.9 (Range: 17.9-45.0) \\
\hline Gender & 128 & $\begin{array}{l}61 \% \text { Female } \\
39 \% \text { Male }\end{array}$ \\
\hline Race/ethnicity & 128 & $\begin{array}{l}\text { 80.5\% White } \\
\text { 13.3\% African American } \\
\text { 5.5\% Asian } \\
0.8 \% \text { Native American }\end{array}$ \\
\hline Partner status & 128 & $\begin{array}{l}66 \% \text { slept with partner } \\
41 \% \text { were members of couples in } \\
\text { the study ( } 26 \text { couples in study) }\end{array}$ \\
\hline
\end{tabular}

$\mathrm{BMI}=$ body mass index .

Subjects slept on each of the seven test mattresses in their own homes. The mattresses were made by the same manufacturer, ensuring consistency in materials and production processes so that the only difference evaluated would be firmness. The innerspring mattresses ranged in firmness to mirror the range typically found in the US marketplace. Each of the subjects in this study used each mattress for approximately 1 month. They were assigned to each mattress using a Latin square randomization system so that subjects were not on consecutively firmer or softer mattresses. Nothing on the mattress would have indicated to the subject the level of firmness when the bed arrived at the home.

To measure sleep duration and efficiency, participants wore a widely accepted monitor called an actigraph
(Ancoli-Israel et al., 2003; Morgenthaler et al., 2007). The American Academy of Sleep Medicine supports the use of actigraphic measurement to identify sleep and wake periods (Littner et al., 2003). To measure pain, sleep quality, daytime drowsiness, and other parameters, participants entered reports in an electronic diary.

\section{Self-Selection of Preferred Mattress}

Before beginning the in-home part of the sleep study, we sought to test whether the typical shopping experience would lead subjects to choose the one mattress that results in best sleep. We simulated a showroom environment where all of the subjects tried each mattress. To maintain the blind study protocol, we arranged the seven study mattresses in random order in the simulated showroom. The participants were blinded to the mattress's manufacturer, construction materials, design, and level of firmness.

We asked them to act as though they were in the market to buy a mattress and to select the one they preferred. As part of the selection process, we encouraged each participant to "test drive" the mattress. They were encouraged to lie on, feel, and evaluate the mattresses. Participants were allowed as much time as they wanted to make their selection (typically they took 10 to 15 minutes) and were able to make notes of their observations. We conducted the mattress self-selection during participant training in a laboratory located in Research Triangle Park, North Carolina.

\section{Statistical Methods}

We began the analysis by ranking the mattresses (referred to in the rest of this section as "beds"), at the participant level, according to their average amount of overnight motion on each bed. This was measured in terms of the number of minutes during which the actigraph measured motion during the night, normalized to 8 hours devoted to sleep. The measure of motion refers to the number of 1-minute intervals in which the actigraph measured any amount of motion, during the time from sleep onset to final arousal, while the subject was lying in bed. We ranked the beds for each individual from best (coded 1) to worst (coded 7), where 1 indicates that Bed $j$ $(j=1, \ldots, 7)$ has least average actigraphic motion for 
subject $i$, and 7 indicates Bed $j$ has greatest actigraphic motion for subject $i$. We call the effect resulting from this mattress ranking the motion bed rank. Based on this ranking, a participant's best motion bed is the mattress with the smallest average motion minutes per night (normalized to 8 hours devoted to sleep).

We used a linear regression model to estimate and compare average overnight motion within each motion bed rank category. This analysis estimates the degree to which motion (reported in minutes) was reduced on the best motion bed as compared with other beds. To conduct the linear regression analyses, we analyzed longitudinal data from all compliant nights on all mattresses from each participant simultaneously in a general linear mixed model (Diggle, Liang, \& Zeger, 1994; Laird \& Ware, 1982; Lindsay, 1993). The outcome variable was overnight motion. The main independent variable of interest-motion bed rank-was modeled as a categorical variable for evaluating the overall motion bed rank effect and as a continuous variable for evaluating a trend effect. The MIXED procedure in SAS Version 9.1.3 (SAS Institute, 2006) was used to account for the correlation of mattresses and nights within participants (Brown \& Prescott, 2006; Senn, 2002). Statistical significance refers to $p<0.05$, and all $p$-values are two-sided.

We used a similar regression modeling approach to evaluate the effect of motion bed rank on eight key diary outcomes, except in these models we also adjusted for the participant's age, gender, BMI, ordinal day on bed, and time spent in bed (also referred to as time devoted to sleep). The diary outcomes are as follows: self-reported sleep time, number of overnight awakenings, minutes awake overnight, sleep quality, level of restedness at start of day (also referred to as well-restedness at start of day), pain upon waking (also referred to as morning pain), daytime sleepiness, and daytime energy. Sleep quality, restedness, morning pain, daytime energy, and daytime sleepiness are self-reports using a 7-point Likert-type scale from least (1) to greatest (7). Minutes awake were categorized and reported using an ordinal scale ( $1=0$ minutes, $2=1-15$ minutes, $3=16-30$ minutes, $4=31-45$ minutes, $5=45-60$ minutes, $6=60+$ minutes). Self-reported sleep time was recorded in minutes.
We evaluated the overall effect of motion bed rank and the trend across bed rank on each of the diaryreported sleep outcomes. We also performed pairwise comparisons among motion bed ranks (best motion bed vs. second-best bed; best motion bed vs. average of all others) and estimated model-adjusted means (also known as least square means) within each motion bed rank category.

An example of the linear regression equation for one sleep outcome, self-reported number of awakenings, is as follows:

$$
\begin{aligned}
& \text { Number of Awakenings } s_{i j k} \\
& =\beta_{0}+\left(\beta_{1} \times \text { Motion Bed Rank } k_{i j}\right) \\
& +\left(\beta_{2} \times \text { Ordinal Day on } \operatorname{Bed}_{i j k}\right) \\
& +\left(\beta_{3} \times \text { Time in } \operatorname{Bed}_{i j k}\right)+\left(\beta_{4} \times \text { Age }_{i}\right) \\
& +\left(\beta_{5} \times \text { Gender }_{i}\right)+\left(\beta_{6} \times \mathrm{BMI}_{i}\right) \\
& +\left(\beta_{7} \times \text { Study Period } 1_{i j k}\right) \\
& +\ldots+\left(\beta_{12} \mathrm{x} \text { Study Period } 6_{i j k}\right) \text {, }
\end{aligned}
$$

where $\beta_{0}-\beta_{12}$ are the regression coefficients to be estimated. The response and independent variables are defined as follows:

\section{- Self-reported number of overnight awakenings}

(response variable measured by the diary, for subject $i$, bed $j$, night $k$ ).

- Motion bed rank (coded 1-7 for subject $i$, bed $j$, modeled as categorical or continuous, depending on whether the hypothesis is to evaluate an overall effect of motion bed rank or to evaluate trend across motion bed rank).

- Ordinal day on bed (this measures the acclimation effect, coded 1 to number of days on bed, modeled as continuous, for subject $i$, bed $j$, night $k$ ).

- Time in bed (amount of time devoted to sleep, in minutes, as determined by actigraphy, modeled as continuous, for subject $i$, bed $j$, night $k$ ).

- Age (in years at entrance into study, modeled as continuous, for subject $i$ ).

- Gender (coded 1 for males, 0 for females, for subject $i$ ).

- BMI (body mass index, or weight $/$ height $^{2}$, modeled as continuous, for subject $i$ ).

- Study period (Latin square crossover design variable, coded 1-7, modeled as categorical, for subject $i$, bed $j$ ). 
Table 2 presents descriptive statistics for the response variables used in the regression analyses and describes the nature of the variables.

In addition to ranking the beds by overnight motion, we also ranked the beds within subject by their average self-reported sleep quality on each bed (averaged over the nights that the subject slept on the bed). Higher values of self-reported sleep quality indicate better sleep on a 7-point scale. Based on this ranking, a participant's best sleep quality bed is the mattress with the highest average sleep quality score. We carried out a similar set of regression analyses as previous, replacing motion bed rank with a ranking based on self-reported sleep quality. Sleep quality bed rank is modeled as continuous (one regression coefficient) for evaluating trend, and modeled as categorical (six regression coefficients) for all other hypotheses.

\section{Participants' Self-Selection of "Best" Mattress}

In the final part of this analysis, we turned our attention to whether the participant's showroom "test drive" provided a means of choosing a mattress that predicts best sleep for that individual. More specifically, we evaluated whether the mattress that individuals had said they would choose for themselves agreed with their optimal mattress as determined by actigraphy and separately by reported sleep quality. Self-reported sleep quality is based on diary reports of sleep quality during his or her inhome testing.

To accomplish this, we estimated the kappa measure of agreement ${ }^{2}$ (Agresti, 2002) between the selfselected bed and the actigraphically determined best bed for each individual and also between the self-selected bed and self-reported best sleep quality bed for each individual. We also estimated the kappa measure of agreement between the self-selected bed and the top 3 best motion beds, based on the observed vs. expected percentage of participants for which the self-selected bed is among the motion bed ranks of 1, 2, or 3 for the participant. Finally, we estimated the mean and median motion bed rank associated with an individual's self-selected bed.

\footnotetext{
2 The kappa statistic measures the extent of agreement between two raters beyond what would be expected by chance alone.
}

\begin{tabular}{|c|c|c|c|c|c|}
\hline Variable (type and measure) & N & $\begin{array}{l}\text { Number } \\
\text { missing }\end{array}$ & Minimum & Mean & Maximum \\
\hline \multicolumn{6}{|l|}{ Actigraph } \\
\hline $\begin{array}{l}\text { Overnight motion in minutes per night (continuous variable } \\
\text { normalized to } 8 \text { hours) }\end{array}$ & 16,366 & 0 & 0 & 61.44 & 316.31 \\
\hline Time in bed devoted to sleep (continuous variable in minutes) & 16,366 & 0 & 32.00 & 447.29 & $1,069.00$ \\
\hline \multicolumn{6}{|l|}{ Diary } \\
\hline Self-reported sleep time (continuous variable in minutes) & 15,941 & 425 & 0 & 433.78 & 888.00 \\
\hline Number of awakenings (continuous) & 14,912 & 1,454 & 0 & 0.95 & 12.00 \\
\hline $\begin{array}{l}\text { Minutes awake overnight (categorized from } 1 \text { to } 6 \text { in } 15 \text {-minute } \\
\text { increments, where } 1=0 \text { minutes and } 6=60+\text { minutes) }\end{array}$ & 15,059 & 1,307 & 1.00 & 1.78 & 6.00 \\
\hline Sleep quality (categorical: $1=$ Not at all; $7=$ Very good sleep) & 16,315 & 51 & 1.00 & 5.08 & 7.00 \\
\hline Well-restedness in AM (categorical: 1=Not at all; 7=Very well rested) & 16,315 & 51 & 1.00 & 4.87 & 7.00 \\
\hline Morning pain (any type) (categorical: $1=$ None; $7=$ Worst imaginable) & 16,282 & 84 & 1.00 & 1.56 & 7.00 \\
\hline Daytime sleepiness (categorical: $1=$ Not at all; $7=$ Very sleepy) & 15,116 & $1,250^{\mathrm{a}}$ & 1.00 & 2.83 & 7.00 \\
\hline Daytime energy (categorical: $1=$ Not at all; $7=$ Very energetic) & 15,116 & $1,250^{\mathrm{a}}$ & 1.00 & 4.86 & 7.00 \\
\hline
\end{tabular}


As in our prior report, the analyses focused on the 128 participants who successfully completed the study (Krystal et al., 2011). The previous report provides complete details on our approach to including or excluding individual observations for analysis.

\section{Results}

\section{Actigraphically Determined Bed Ranking (Motion Bed Rank)}

The best motion bed was relatively evenly distributed across mattresses in our sample. Figure 1 depicts the frequency distribution of the actigraphically determined best bed across mattresses. Table 3 presents the results of the regression modeling (SAS MIXED procedure). The first row of that table determines the extent to which actigraph-measured motion per night is lower on the best motion bed compared to other beds. The results in the columns labeled Bed Rank 1 through Bed Rank 7 report the (model-adjusted) means for actigraphic and diary measures. The Bed Rank 1 column indicates that the mean overnight minutes of motion per 8 hours was slightly more than 54 minutes on the actigraphically determined best bed (Bed Rank 1). The Bed Rank 7 column reports that on average, actigraphic measurement found nearly 69 minutes of overnight motion on the worst bed (Bed Rank 7). This is a difference of 15 minutes and is statistically significant $(p=0.0001)$.

\section{Figure 1. Frequency distribution of best motion bed}

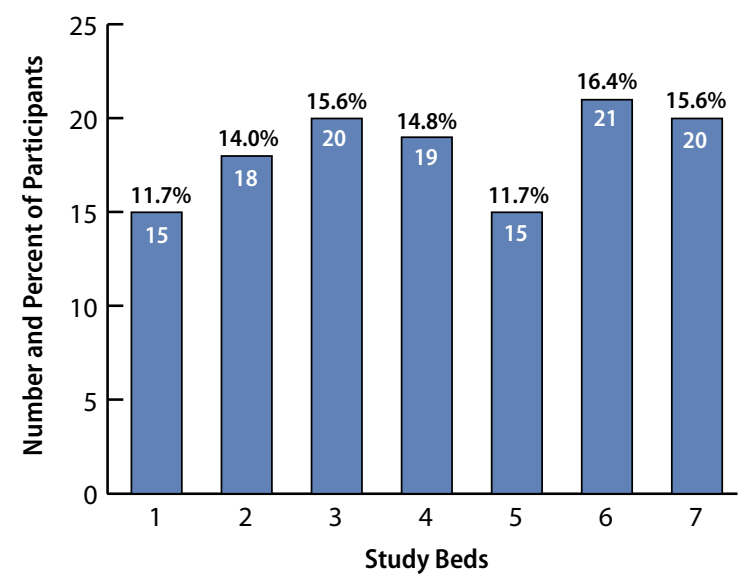

In Table 3, the rightmost column indicates that the best motion bed on average is associated with 3.26 fewer minutes of motion than the second-best bed. This difference is statistically significant $(p=0.0001)$. This column also reports that the best bed is associated with 8.3 fewer minutes of motion than the average of all other beds in the motion ranking (second through seventh), and this, too, is statistically significant $(p=0.0001)$.

Although the differences in total motion are numerically small, analysis of the effect of motion bed rank on diary outcomes indicates that the bed with lowest motion was significantly associated with better sleep quality, better feeling of restedness at the start of the day, improved daytime energy, fewer nighttime awakenings, and fewer minutes awake.

Self-reported sleep quality was significantly improved on the bed with the least overnight motion compared with the bed with the second-lowest motion ( $p=0.0048)$ and with the average of all other beds $(p=0.0010)$. In addition, sleep quality decreased linearly with bed rank $(p=0.0001)$. Average scores for sleep quality ranged from 5.13 on the best motion bed, to 5.05 on the second-best bed, to 4.99 on the worst bed, out of a Likert-type scale of 1 (not at all good) to 7 (very good).

Self-reported level of restedness was significantly improved on the best motion bed compared with the average of all other beds ( $p=0.0193)$, and restedness also decreased linearly with bed rank $(p=0.0078)$. Average scores for restedness ranged from 4.91 and 4.87 on the best and second-best motion beds to 4.81 on the worst bed, out of a Likert-type scale of 1 (not at all rested) to 7 (very well rested).

Self-reported daytime energy increased linearly with bed rank, such that daytime energy tended to increase in beds ranked higher on actigraphic sleep $(p=0.0016)$. However, daytime energy on the best motion bed was only marginally increased when compared to the average of all other beds $(p=0.0574)$. The average score for daytime energy ranged from 4.90 and 4.88 on the best and second-best motion beds to 4.81 on the worst bed, out of a Likert-type scale of 1 (not at all energetic) to 7 (very energetic). 


\begin{tabular}{|c|c|c|c|c|c|c|c|c|c|}
\hline \multirow{2}{*}{$\begin{array}{l}\text { Sleep } \\
\text { Response } \\
\text { Variable }\end{array}$} & \multicolumn{7}{|c|}{ Model-Adjusteda Mean (SE) } & \multirow{2}{*}{$\begin{array}{l}\text { Overall } \\
\text { Bed Rank } \\
p \text {-value }\end{array}$} & \multirow{2}{*}{$\begin{array}{l}\text { Rank } 1 \text { vs. } 2^{b} \\
\text { Rank } 1 \text { vs. All Othersc } \\
\text { Linear Trendd }\end{array}$} \\
\hline & $\begin{array}{c}\text { Bed } \\
\text { Rank } 1\end{array}$ & $\begin{array}{c}\text { Bed } \\
\text { Rank } 2\end{array}$ & $\begin{array}{c}\text { Bed } \\
\text { Rank } 3\end{array}$ & $\begin{array}{c}\text { Bed } \\
\text { Rank } 4\end{array}$ & $\begin{array}{c}\text { Bed } \\
\text { Rank } 5\end{array}$ & $\begin{array}{c}\text { Bed } \\
\text { Rank } 6\end{array}$ & $\begin{array}{c}\text { Bed } \\
\text { Rank } 7\end{array}$ & & \\
\hline \multicolumn{10}{|l|}{ Actigraph } \\
\hline $\begin{array}{l}\text { Overnight minutes } \\
\text { of motion per } \\
8 \text { hours }\end{array}$ & $\begin{array}{l}54.35 \\
(1.63)\end{array}$ & $\begin{array}{l}57.61 \\
(1.63)\end{array}$ & $\begin{array}{l}59.62 \\
(1.63)\end{array}$ & $\begin{array}{l}61.51 \\
(1.63)\end{array}$ & $\begin{array}{l}63.42 \\
(1.63)\end{array}$ & $\begin{array}{l}65.21 \\
(1.63)\end{array}$ & $\begin{array}{l}68.53 \\
(1.63)\end{array}$ & 0.0001 & $\begin{array}{l}-3.26(0.38) p=0.0001 \\
-8.30(0.29) p=0.0001 \\
2.20(0.05) p=0.0001\end{array}$ \\
\hline \multicolumn{10}{|l|}{ Diary (Self-Report) } \\
\hline $\begin{array}{l}\text { Sleep time } \\
\text { (minutes) }\end{array}$ & $\begin{array}{l}435.03 \\
(2.33)\end{array}$ & $\begin{array}{r}435.01 \\
(2.33)\end{array}$ & $\begin{array}{c}433.05 \\
(2.32)\end{array}$ & $\begin{array}{c}433.65 \\
(2.33)\end{array}$ & $\begin{array}{r}432.01 \\
(2.32)\end{array}$ & $\begin{array}{l}432.69 \\
(2.33)\end{array}$ & $\begin{array}{c}433.59 \\
(2.33)\end{array}$ & NS & $\begin{array}{l}\text { NS } \\
\text { NS } \\
-0.36(0.19) p=0.0595\end{array}$ \\
\hline $\begin{array}{l}\text { Number of } \\
\text { awakenings }\end{array}$ & $\begin{array}{c}0.9054 \\
(0.0702)\end{array}$ & $\begin{array}{c}0.9886 \\
(0.0702)\end{array}$ & $\begin{array}{c}0.9268 \\
(0.0700)\end{array}$ & $\begin{array}{c}0.9246 \\
(0.0701)\end{array}$ & $\begin{array}{c}0.9725 \\
(0.0700)\end{array}$ & $\begin{array}{c}0.9921 \\
(0.0701)\end{array}$ & $\begin{array}{c}1.0493 \\
(0.0701)\end{array}$ & 0.0001 & $\begin{array}{l}-0.08(0.03) p=0.0039 \\
-0.07(0.02) p=0.0015 \\
0.0175(0.0039) p=0.0000\end{array}$ \\
\hline $\begin{array}{l}\text { Minutes awake } \\
\text { overnight }\end{array}$ & $\begin{array}{c}1.72 \\
(0.05)\end{array}$ & $\begin{array}{c}1.76 \\
(0.05)\end{array}$ & $\begin{array}{c}1.73 \\
(0.05)\end{array}$ & $\begin{array}{l}1.79 \\
(0.05)\end{array}$ & $\begin{array}{c}1.83 \\
(0.05)\end{array}$ & $\begin{array}{c}1.81 \\
(0.05)\end{array}$ & $\begin{array}{c}1.88 \\
(0.05)\end{array}$ & 0.0001 & $\begin{array}{l}\text { NS } \\
-0.08(0.02) p=0.0002 \\
0.025(0.004) p=0.0000\end{array}$ \\
\hline Sleep quality & $\begin{array}{c}5.13 \\
(0.07)\end{array}$ & $\begin{array}{l}5.05 \\
(0.07)\end{array}$ & $\begin{array}{l}5.08 \\
(0.07)\end{array}$ & $\begin{array}{c}5.10 \\
(0.07)\end{array}$ & $\begin{array}{c}5.07 \\
(0.07)\end{array}$ & $\begin{array}{c}5.07 \\
(0.07)\end{array}$ & $\begin{array}{c}4.99 \\
(0.07)\end{array}$ & 0.0001 & $\begin{array}{l}0.08(0.03) p=0.0048 \\
0.07(0.02) p=0.0010 \\
-0.015(0.004) p=0.0001\end{array}$ \\
\hline Well-restedness & $\begin{array}{l}4.91 \\
(0.07)\end{array}$ & $\begin{array}{l}4.87 \\
(0.07)\end{array}$ & $\begin{array}{l}4.88 \\
(0.07)\end{array}$ & $\begin{array}{l}4.88 \\
(0.07)\end{array}$ & $\begin{array}{l}4.87 \\
(0.07)\end{array}$ & $\begin{array}{l}4.88 \\
(0.07)\end{array}$ & $\begin{array}{l}4.81 \\
(0.07)\end{array}$ & 0.0347 & $\begin{array}{l}\text { NS } \\
0.05(0.02) p=0.0193 \\
-0.01(0.004) p=0.0078\end{array}$ \\
\hline $\begin{array}{l}\text { Morning pain } \\
\text { severity }\end{array}$ & $\begin{array}{l}1.53 \\
(0.06)\end{array}$ & $\begin{array}{c}1.56 \\
(0.06)\end{array}$ & $\begin{array}{c}1.51 \\
(0.06)\end{array}$ & $\begin{array}{l}1.55 \\
(0.06)\end{array}$ & $\begin{array}{l}1.60 \\
(0.06)\end{array}$ & $\begin{array}{c}1.53 \\
(0.06)\end{array}$ & $\begin{array}{l}1.56 \\
(0.06)\end{array}$ & 0.0263 & $\begin{array}{l}\text { NS } \\
\text { NS } \\
\text { NS }\end{array}$ \\
\hline Daytime sleepiness & $\begin{array}{c}2.78 \\
(0.08)\end{array}$ & $\begin{array}{c}2.82 \\
(0.08)\end{array}$ & $\begin{array}{c}2.81 \\
(0.08)\end{array}$ & $\begin{array}{c}2.85 \\
(0.08)\end{array}$ & $\begin{array}{c}2.76 \\
(0.08)\end{array}$ & $\begin{array}{c}2.77 \\
(0.08)\end{array}$ & $\begin{array}{l}2.90 \\
(0.08)\end{array}$ & 0.0002 & $\begin{array}{l}\text { NS } \\
\text { NS } \\
\text { NS }\end{array}$ \\
\hline Daytime energy & $\begin{array}{l}4.90 \\
(0.08)\end{array}$ & $\begin{array}{l}4.88 \\
(0.08)\end{array}$ & $\begin{array}{l}4.85 \\
(0.08)\end{array}$ & $\begin{array}{c}4.93 \\
(0.08)\end{array}$ & $\begin{array}{l}4.90 \\
(0.08)\end{array}$ & $\begin{array}{c}4.84 \\
(0.08)\end{array}$ & $\begin{array}{l}4.81 \\
(0.08)\end{array}$ & 0.0001 & $\begin{array}{l}\text { NS } \\
0.04(0.02) p=0.0574 \\
-0.01(0.003) p=0.0016\end{array}$ \\
\hline
\end{tabular}

$\mathrm{BMI}=$ body mass index; NS = not statistically significant $(p>0.05) ; \mathrm{SE}=$ standard error.

a Diary means within levels of motion bed rank are adjusted for the following model covariates: Ordinal Day in Bed, Time in Bed, Age, Gender, BMI, and Study Period.

b Bed Rank 1 minus Bed Rank 2: Estimated difference, SE, and $p$-value (2-sided).

c Bed Rank 1 minus average of Bed Ranks 2-7: Estimated difference, SE, and $p$-value (2-sided).

d Linear trend across Bed Ranks (1=Best, 7=Worst): Estimated slope, SE, and $p$-value (2-sided).

e Means within levels of motion bed rank are not adjusted for any covariates. They are included as descriptive information.

NOTE: Bed Rank 1 indicates least overnight motion measured by actigraphy, and Bed Rank 7 indicates greatest motion measured by actigraphy. All analyses carried out using the SAS MIXED procedure.

\section{Self-reported number of nighttime awakenings}

were significantly reduced on the best motion bed compared with second best $(p=0.0039)$ and compared with the average of all other beds $(p=0.0015)$. The reduction in awakenings were also linearly related to motion bed rank $(p<0.0001)$. The average number of nighttime awakenings ranged from 0.91 and 0.99 on the best and second-best motion beds to 1.05 on the worst bed.

\section{Self-reported number of minutes awake overnight} was also significantly reduced on the best motion bed compared to the average of all other beds $(p=0.0002)$, and the reduction in minutes awake overnight was also linearly related to motion bed rank $(p<0.0001)$. The average number of minutes awake overnight (categorized in 15-minute increments from $1=0$ minutes, $2=1-15$ minutes, $\ldots, 6=60+$ minutes) ranged from 1.72 and 1.76 on the best and second-best motion beds to 1.88 on the worst bed. 


\section{Sleep Quality Bed Ranking}

Table 4 reports the results of a similar analysis identifying the "best bed" as determined by the diary measure of overnight sleep quality. In the first row of the table, the columns labeled Bed Rank 1 through Bed Rank 7 report self-report sleep quality means along the Likert scale where 1 is worst sleep quality and 7 is best. On average, all bed ranks rate above the midpoint (4), with the best sleep quality bed on average rated 5.6 on the scale and the second-best rated 5.41. The lowest rating bed had a sleep quality score of 4.32. The far-right column indicates an average increase of 0.19 ( 3.5 percent improvement) in sleep quality between the best and second-best sleep quality bed $(p<0.0001)$. This column also indicates an increase of 0.65 ( 13 percent improvement) in sleep quality on the best bed compared with the average of the remaining bed ranks ( $p<0.0001)$. Sleep quality decreased linearly with bed rank $(p<0.0001)$.

Most importantly, there was a significant relationship between sleep quality bed rank and actigraphic

\begin{tabular}{|c|c|c|c|c|c|c|c|c|c|}
\hline \multirow{2}{*}{$\begin{array}{l}\text { Sleep } \\
\text { Response } \\
\text { Variable }\end{array}$} & \multicolumn{7}{|c|}{ Model-Adjusteda Mean (SE) } & \multirow{2}{*}{$\begin{array}{l}\text { Overall } \\
\text { Bed Rank } \\
p \text {-value }\end{array}$} & \multirow{2}{*}{$\begin{array}{l}\text { Rank } 1 \text { vs. } 2^{\text {b }} \\
\text { Rank } 1 \text { vs. All Othersc } \\
\text { Linear Trendd }\end{array}$} \\
\hline & $\begin{array}{c}\text { Bed } \\
\text { Rank } 1\end{array}$ & $\begin{array}{c}\text { Bed } \\
\text { Rank } 2\end{array}$ & $\begin{array}{c}\text { Bed } \\
\text { Rank } 3\end{array}$ & $\begin{array}{c}\text { Bed } \\
\text { Rank } 4\end{array}$ & $\begin{array}{c}\text { Bed } \\
\text { Rank } 5\end{array}$ & $\begin{array}{c}\text { Bed } \\
\text { Rank } 6\end{array}$ & $\begin{array}{c}\text { Bed } \\
\text { Rank } 7\end{array}$ & & \\
\hline Sleep Qualitye & $\begin{array}{l}5.60 \\
(0.07)\end{array}$ & $\begin{array}{l}5.41 \\
(0.07)\end{array}$ & $\begin{array}{c}5.24 \\
(0.07)\end{array}$ & $\begin{array}{l}5.10 \\
(0.07)\end{array}$ & $\begin{array}{c}4.93 \\
(0.07)\end{array}$ & $\begin{array}{c}4.74 \\
(0.07)\end{array}$ & $\begin{array}{c}4.32 \\
(0.07)\end{array}$ & $<.0001$ & $\begin{array}{l}0.19(0.03) p<0.0001 \\
0.65(0.02) p<0.0001 \\
-0.20(0.0050) p<0.0001\end{array}$ \\
\hline \multicolumn{10}{|l|}{ Actigraph } \\
\hline $\begin{array}{l}\text { Overnight minutes } \\
\text { of motion per } \\
8 \text { hours }\end{array}$ & $\begin{array}{l}61.53 \\
(1.64)\end{array}$ & $\begin{array}{l}61.97 \\
(1.64)\end{array}$ & $\begin{array}{l}62.54 \\
(1.64)\end{array}$ & $\begin{array}{l}62.55 \\
(1.64)\end{array}$ & $\begin{array}{l}62.21 \\
(1.64)\end{array}$ & $\begin{array}{l}63.12 \\
(1.64)\end{array}$ & $\begin{array}{l}62.62 \\
(1.64)\end{array}$ & 0.0233 & $\begin{array}{l}-0.43(0.46) p=0.3501 \\
-0.97(0.34) p=0.0055 \\
0.19(0.06) p=0.0023\end{array}$ \\
\hline \multicolumn{10}{|l|}{ Diary (Self-Report) } \\
\hline $\begin{array}{l}\text { Sleep time } \\
\text { (minutes) }\end{array}$ & $\begin{array}{r}434.41 \\
(2.31)\end{array}$ & $\begin{array}{c}436.55 \\
(2.33)\end{array}$ & $\begin{array}{c}434.69 \\
(2.32)\end{array}$ & $\begin{array}{c}432.56 \\
(2.33)\end{array}$ & $\begin{array}{c}433.08 \\
(2.34)\end{array}$ & $\begin{array}{c}430.98 \\
(2.33)\end{array}$ & $\begin{array}{c}432.36 \\
(2.35)\end{array}$ & 0.0021 & $\begin{array}{l}-2.14(1.37) p=0.1210 \\
1.04(1.03) p=0.3156 \\
-0.68(0.18) p=0.0003\end{array}$ \\
\hline $\begin{array}{l}\text { Number of } \\
\text { awakenings }\end{array}$ & $\begin{array}{c}0.80 \\
(0.07)\end{array}$ & $\begin{array}{c}0.87 \\
(0.07)\end{array}$ & $\begin{array}{c}0.92 \\
(0.07)\end{array}$ & $\begin{array}{c}0.96 \\
(0.07)\end{array}$ & $\begin{array}{c}0.95 \\
(0.07)\end{array}$ & $\begin{array}{c}1.08 \\
(0.07)\end{array}$ & $\begin{array}{c}1.23 \\
(0.07)\end{array}$ & $<.0001$ & $\begin{array}{l}-0.07(0.02) p=0.0168 \\
-0.20(0.02) p<0.0001 \\
0.06(0.0038) p=<0.0001\end{array}$ \\
\hline $\begin{array}{l}\text { Minutes awake } \\
\text { overnight }\end{array}$ & $\begin{array}{c}1.66 \\
(0.05)\end{array}$ & $\begin{array}{c}1.68 \\
(0.05)\end{array}$ & $\begin{array}{c}1.76 \\
(0.05)\end{array}$ & $\begin{array}{c}1.78 \\
(0.05)\end{array}$ & $\begin{array}{c}1.80 \\
(0.05)\end{array}$ & $\begin{array}{c}1.90 \\
(0.05)\end{array}$ & $\begin{array}{c}1.98 \\
(0.05)\end{array}$ & $<.0001$ & $\begin{array}{l}-0.02(0.02) p=0.5018 \\
-0.16(0.02) p<0.0001 \\
0.05(0.0037) p<0.0001\end{array}$ \\
\hline Well-restedness & $\begin{array}{c}5.27 \\
(0.07)\end{array}$ & $\begin{array}{c}5.15 \\
(0.07)\end{array}$ & $\begin{array}{c}5.02 \\
(0.07)\end{array}$ & $\begin{array}{c}4.89 \\
(0.07)\end{array}$ & $\begin{array}{c}4.76 \\
(0.07)\end{array}$ & $\begin{array}{l}4.57 \\
(0.07)\end{array}$ & $\begin{array}{c}4.32 \\
(0.07)\end{array}$ & $<.0001$ & $\begin{array}{l}0.12(0.02) p<0.0001 \\
0.49(0.01) p<0.0001 \\
-0.15(0.0034) p<0.0001\end{array}$ \\
\hline $\begin{array}{l}\text { Morning pain } \\
\text { severity }\end{array}$ & $\begin{array}{c}1.34 \\
(0.06)\end{array}$ & $\begin{array}{c}1.42 \\
(0.06)\end{array}$ & $\begin{array}{c}1.51 \\
(0.06)\end{array}$ & $\begin{array}{c}1.48 \\
(0.06)\end{array}$ & $\begin{array}{c}1.59 \\
(0.06)\end{array}$ & $\begin{array}{c}1.70 \\
(0.06)\end{array}$ & $\begin{array}{c}1.86 \\
(0.06)\end{array}$ & $<.0001$ & $\begin{array}{l}-0.08(0.02) p=0.0029 \\
-0.25(0.02) p<0.0001 \\
0.08(0.0036) p<0.0001\end{array}$ \\
\hline $\begin{array}{l}\text { Daytime } \\
\text { sleepiness }\end{array}$ & $\begin{array}{c}2.64 \\
(0.08)\end{array}$ & $\begin{array}{c}2.71 \\
(0.08)\end{array}$ & $\begin{array}{c}2.76 \\
(0.08)\end{array}$ & $\begin{array}{c}2.83 \\
(0.08)\end{array}$ & $\begin{array}{c}2.82 \\
(0.08)\end{array}$ & $\begin{array}{c}2.96 \\
(0.08)\end{array}$ & $\begin{array}{c}3.00 \\
(0.08)\end{array}$ & $<.0001$ & $\begin{array}{l}-0.07(0.03) p=0.0401 \\
-0.20(0.02) p<0.0001 \\
0.06(0.0045) p<0.0001\end{array}$ \\
\hline Daytime energy & $\begin{array}{c}5.04 \\
(0.08)\end{array}$ & $\begin{array}{c}5.02 \\
(0.08)\end{array}$ & $\begin{array}{c}4.93 \\
(0.08)\end{array}$ & $\begin{array}{c}4.89 \\
(0.08)\end{array}$ & $\begin{array}{c}4.79 \\
(0.08)\end{array}$ & $\begin{array}{c}4.76 \\
(0.08)\end{array}$ & $\begin{array}{c}4.63 \\
(0.08)\end{array}$ & $<.0001$ & $\begin{array}{l}0.02(0.02) p=0.4659 \\
0.20(0.01) p<0.0001 \\
-0.07(0.0033) p<0.0001\end{array}$ \\
\hline
\end{tabular}

$\mathrm{BMI}=$ body mass index; $\mathrm{NS}=$ not statistically significant $(p>0.05) ; \mathrm{SE}=$ standard error

a Means within levels of Sleep Quality Bed Rank are adjusted for the following model covariates: Ordinal Day in Bed, Time in Bed, Age, Gender, BMI, and Study Period.

b Bed Rank 1 minus Bed Rank 2: Estimated difference, SE, and $p$-value (2-sided).

c Bed Rank 1 minus average of Bed Ranks 2-7: Estimated difference, SE, and $p$-value (2-sided).

d Linear trend across Bed Ranks (1=Best, 7=Worst): Estimated slope, $\mathrm{SE}$, and $p$-value (2-sided).

e Means not adjusted for any covariates. They are included as descriptive information.

NOTE: Bed Rank 1 indicates highest sleep quality measured by diary, and Bed Rank 7 indicates lowest sleep quality measured by diary. All analyses carried out in the SAS MIXED procedure. 
motion ( $p=0.0233)$ as well as many diary outcomes, most notably number of awakenings $(p<0.0001)$, number of minutes awake overnight (categorized) $(p<0.0001)$, well-restedness $(p<0.0001)$, morning pain severity $(p<0.0001)$, daytime sleepiness $(p<0.0001)$, and daytime energy $(p<0.0001)$. After adjusting for covariates, actigraphic motion minutes was significantly reduced in the best sleep quality bed compared to the average of all other bed ranks, and motion increased linearly with bed rank. The beds ranked best and second-best for self-reported sleep quality are also the two beds with the lowest level of actigraphically measured motion.

\section{The number of awakenings and minutes awake} overnight were both significantly reduced in the best sleep quality bed compared to the average of all other bed ranks, with each increasing linearly with bed rank. The number of awakenings was also significantly reduced in the best sleep quality bed compared to second best. Well-restedness and daytime energy were both significantly improved in the best sleep quality bed compared to the average of all other bed ranks, with each decreasing linearly with bed rank. Well-restedness was also significantly improved in the best sleep quality bed compared to second best. Finally, morning pain severity and daytime sleepiness were both significantly reduced in the best sleep quality bed compared to the second best bed and compared to the average of all other bed ranks, with each increasing linearly with bed rank.

\section{Self-Selected Versus Actigraphically Determined Best Bed}

We conducted a series of analyses to determine whether the mattress that individuals indicated they would choose for themselves was predictive of their optimal mattress (or mattresses) as determined by either actigraphy or self-reported sleep quality. In other words, can people predict their optimal mattress from a typical in-store experience? Results indicate that standard showroom testing does not lead individuals to select the bed that will provide their best sleep as measured by either self-reported sleep quality or actigraphic measurement over an extended period of time. Although the self-selected bed varied in our sample (see Figure 1), it was associated with a median motion bed rank of only
4 out of 7 (i.e., mid-rank), and the same was true for self-reported sleep quality (Table 5). Consistent with this, the kappa measure of agreement between the best motion bed and self-select bed was not significantly different from 0 , indicating no additional agreement than what would be expected by chance alone (Table 6). Agreement between self-select bed and the top 3 best motion beds (motion bed rank of 1,2 , or 3 ) was also not significantly different from 0 (Table 7), as the percentage of participants whose self-select bed was among the top 3 motion best beds was only 38 percent (vs. 43 percent expected by chance alone). This suggests that the customary showroom "test drive" in fact often leads consumers to suboptimal mattress selection.

\begin{tabular}{lllll}
\hline \multicolumn{3}{l}{$\begin{array}{l}\text { Table 5. Average motion bed rank and self-reported } \\
\text { sleep quality bed rank of self-selected bed }\end{array}$} \\
$\begin{array}{l}\text { Variable Used } \\
\begin{array}{l}\text { to Determine } \\
\text { Bed Rank }\end{array}\end{array}$ & $\begin{array}{c}\text { Statistic } \\
\text { Estimated } \\
\text { Bed Rank } \\
\text { (1-7) }\end{array}$ & $\begin{array}{c}\text { Lower 95\% } \\
\text { Limit }\end{array}$ & $\begin{array}{c}\text { Upper 95\% } \\
\text { Limit }\end{array}$ \\
\hline $\begin{array}{l}\text { Actigraphic } \\
\begin{array}{l}\text { Motion } \\
\text { (in minutes) }\end{array}\end{array}$ & Average & 4.172 & 3.826 & 4.518 \\
\cline { 2 - 5 } & Median & 4.000 & 4.000 & 5.000 \\
\hline $\begin{array}{l}\text { Self-Reported } \\
\text { leep Quality } \\
\text { (coded 1-7) }\end{array}$ & Average & 3.875 & 3.525 & 4.225 \\
\cline { 2 - 5 } & Median & 4.000 & 3.000 & 4.000 \\
\hline
\end{tabular}

a Actigraphic motion is number of minutes of recorded overnight motion, normalized to an 8-hour night.

\section{Table 6. Agreement between self-selected bed and best motion bed

\begin{tabular}{lccc}
$\begin{array}{l}\text { Methods } \\
\text { Compared }\end{array}$ & $\begin{array}{c}\text { Kappa } \\
\text { Estimate }\end{array}$ & $\begin{array}{c}\text { Lower 95\% } \\
\text { Limit }\end{array}$ & $\begin{array}{c}\text { Upper 95\% } \\
\text { Limit }\end{array}$ \\
$\begin{array}{l}\text { Self-Select vs. Best } \\
\text { Motiona Bed }\end{array}$ & -0.0114 & -0.0795 & 0.0567 \\
\hline
\end{tabular}

a Best motion bed is the mattress firmness with the smallest average overnight motion minutes per 8 hours.

Table 7. Agreement between self-selected bed and top 3 best motion beds

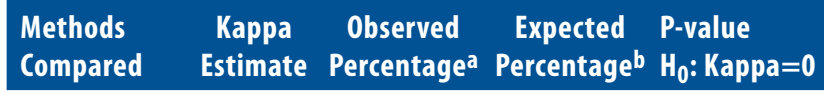

Self-Select vs.

$\begin{array}{lllll}\text { Top } 3 \text { Best } & -0.0801 & 38.28 \% & 42.86 \% & 0.2904\end{array}$ Motion' Beds

a Observed percentage of people for which self-select bed is among the top 3 best motion beds (motion bed ranks 1, 2, or 3).

b Expected percentage of people for which self-select bed is among the top 3 best motion beds (motion bed ranks 1, 2, or 3 ).

c The top 3 best motion beds are the three mattress firmness levels with the smallest average overnight motion minutes per 8 hours. 


\section{Discussion}

Our prior report documented that mattress firmness has significant effects on sleep and daytime function (Krystal et al., 2011). Very low and very high levels of firmness tended to be associated with relatively worse sleep, greater morning pain, and poorer daytime function.

Our results build on those observations. We provide here six main conclusions from our blinded, controlled study:

1. Individuals differ as to the degree of mattress firmness that is associated with their best sleep.

2. Actigraphic activity level has significant utility for identifying the best mattress for an individual (Table 3).

3. The best bed as measured by actigraphic motion significantly minimizes self-reported number of overnight awakenings and minutes awake overnight, and significantly maximizes selfreported sleep quality and well-restedness in the morning (Table 3).

4. The best bed as determined by self-reported sleep quality in the morning significantly minimizes actigraphic motion, self reported number of awakenings, minutes awake overnight, and morning pain severity, and maximizes wellrestedness, daytime sleepiness, and daytime energy (Table 4).

5. People are essentially left to chance when trying to select a mattress using the generally recommended "test drive" on the showroom floor (Tables 5-7).

6. The actigraphically best mattress was well distributed among the sample of participants and across the seven mattresses studied.

These data indicate that activity level is not a reflection of mattress firmness; rather, it provides an indication of the mattress that yields optimal sleep for an individual. This is consistent with our previously reported finding that activity level was not significantly correlated with mattress firmness (Krystal et al., 2011). Thus, our findings imply that improving sleep in many individuals by improving mattress fit is quite possible. Our results also suggest that actigraphically determined activity level may have some utility in this regard.

These observations suggest that improving mattress fit may improve sleep. Pain, daytime sleepiness, and energy level appear to be affected more by mattress firmness than by the degree to which firmness is suitable for an individual. This may reflect the fact that we excluded individuals with pain, insomnia, or daytime sleepiness from this study. Assessing the effects of mattress fit on these measures in studies that include such individuals is an important question for future research.

The mattress that individuals chose as optimal before the randomized, controlled phase of the study did not predict either the actigraphically determined best mattress or the best mattress as determined by reported sleep quality. This finding raises the possibility that the ordinary showroom experience does not lead individuals to select the mattress that results in best sleep over a more extended period. This finding should inspire study into ways in which consumers can be better equipped to identify mattresses that lead to optimal sleep, and the health benefits that come from better rest.

In summary, our study indicates that optimal mattress firmness varies among individuals and is reflected, at least to a degree, by actigraphic activity level. When allowed to test mattresses in a typical showroom experience, individuals appear to choose mattresses that do not optimize their sleep. Given that this "test drive" approach is commonplace, it would seem that most of the general public may be sleeping on mattresses improperly suited to the individual owners. This would help explain to some extent why so many Americans are not enjoying the health benefits that come from optimal rest. Sleep science could assist bedding retailers in improving their customers' sleep outcomes by developing better in-store methods of aiding in the mattress selection process. 


\section{References}

Agresti, A. (2002). Categorical data analysis, 2nd ed. New York: John Wiley and Sons.

Alapin, I., Fichten, C. S., Libman, E., Creti, L., Bailes, S., \& Wright, J. (2001). How is good and poor sleep in older adults and college students related to daytime sleepiness, fatigue and ability to concentrate? Journal of Psychosomatic Research, 49(5), 381-390.

Ancoli-Israel, S., Cole, R., Alessi, C., Chambers, M., Moorcroft, \& Pollak, C. P. (2003). The role of actigraphy in the study of sleep and circadian rhythms. Sleep, 3, 342-392.

Better Sleep Council. (2008a). Consumer attitudes about mattresses are evolving, but purchasing behavior is slow to change. Sleep Savvy, April.

Better Sleep Council. (2008b). Mattress buying guide. Available at http://www.bettersleep.org/Ease /shop.asp

Brown, H., \& Prescott, R. (2006). Applied mixed models in medicine, 2nd ed. New York: John Wiley and Sons.

Centers for Disease Control and Prevention (CDC). (2007). Sleep and sleep disorders: Sleep hygiene tips. Available at http://www.cdc.gov/sleep /hygiene.htm

Consumer Reports. (2005). How to buy a mattress without losing sleep. June, 12-17.

Diggle, P. J., Liang, K. Y., \& Zeger, S. L. (1994). Analysis of longitudinal data. Oxford: Oxford University Press.

Elmenhorst, E. M., Elmenhorst, D., Luks, N., Maass, H., Vejvoda, M., \& Samel, A. (2008). Partial sleep deprivation: Impact on the architecture and quality of sleep. Sleep Medicine, 8, 840-850.

Hamilton, N. A., Gallagher, M. W., Preacher, K. J., Stevens, N., Nelson, C. A., Karlson, C., \& McCurdy, D. (2007). Insomnia and well being. Journal of Consulting \& Clinical Psychology, 75, 939-946.
Hanel, S. E., Dartman, T., \& Shishoo, R. (1996). Measuring methods for comfort rating of seats and beds. International Journal of Industrial Ergonomics, 20, 163-172.

Krystal, A. Edinger, J., Bieler, G., Mladsi, S., \& Hogan, S. (2011). Mattress matters: A randomized, controlled, Latin-square crossover study of the effects of mattress support on sleep, pain, and daytime functioning. Research Triangle Park, NC: RTI Press.

Laird, N. M., \& Ware, J. H. (1982). Random effects models for longitudinal data. Biometrics, 38, 963-974.

Lindsay, J. (1993). Models for repeated measurements. Oxford: Oxford University Press.

Littner, M. Kushida, C. A., Anderson, W. M., Bailey, D., Berry, R. B., Davila, D. G., Hirshkowitz, M., Kapen, S., Kramer, M., Loube, D., Wise, M., \& Johnson, S. F. (2003). Practice parameters for the role of actigraphy in the study of sleep and circadian rhythms: An update for 2002. Sleep, 26, 337-341.

López-Torres, M., Porcar, R., Solaz, J., \& Romero, T. (2008). Objective firmness, average pressure and subjective perception in mattresses for the elderly. Applied Ergonomics, 39, 123-130.

Morgenthaler, T., Alessi, C., Friedman, L., Owens, J., Kapur, V., Boehlecke, B., Brown, T., Chesson, A. Jr., Coleman, J., Lee-Chiong, T., Pancer, J., \& Swick, T. J. (2007). Practice parameters for the use of actigraphy in the assessment of sleep and sleep disorders: An update for 2007. Sleep, 30(4), 519-529.

National Institutes of Health (NIH), National Institute of Neurological Disorders and Stroke. (2003a). Brain basics: Understanding sleep. Bethesda, MD: National Institute of Neurological Disorders and Stroke.

National Institutes of Health (NIH), National Center for Sleep Disorders Research. (2003b). National sleep disorders research plan. NIH Report No. 03-5209. Bethesda, MD: National Institute of Neurological Disorders and Stroke. 
Roberts, R. E., Roberts, C. R., \& Duong, H. T. (2008). Chronic insomnia and its negative consequences for health and functioning of adolescents: A 12-month prospective study. Journal of Adolescent Health, 42, 294-302.

SAS Institute Inc. (2006). SAS/STAT user's guide, Version 9.1.3. Cary, NC: SAS Institute Inc.
Senn, S. (2002). Cross-over trials in clinical research, 2nd ed. New York: John Wiley and Sons.

Van Dongen, H. P., Maislin, G., Mullington, J. M., \& Dinges, D. F. (2003). The cumulative cost of additional wakefulness: Dose-response effects on neurobehavioral functions and sleep physiology from chronic sleep restriction and total sleep deprivation. Sleep, 2, 117-126. 


\section{Acknowledgments}

Sleep to Live Institute of Joplin, Missouri, sponsored this research. Sleep to Live Institute did not exercise editorial control over the analysis or reporting of the results. We recognize the contributions of Michael S.S. Lawrence, Jeff Barghout, and Scott Mladsi in the design and implementation of this experiment. 
RTI International is an independent, nonprofit research organization dedicated to improving the human condition by turning knowledge into practice. RTI offers innovative research and technical solutions to governments and businesses worldwide in the areas of health and pharmaceuticals, education and training, surveys and statistics, advanced technology, international development, economic and social policy, energy and the environment, and laboratory and chemistry services.

The RTI Press complements traditional publication outlets by providing another way for RTI researchers to disseminate the knowledge they generate. This PDF document is offered as a public service of RTI International. 